\title{
A Comparison of Users and Nonusers of a Web-Based Intervention for Carers of Older Persons With Alzheimer Disease and Related Dementias: Mixed Methods Secondary Analysis
}

Wendy Duggleby ${ }^{1}, \mathrm{PhD}$; Jenny Ploeg ${ }^{2}$, PhD; Carrie McAiney ${ }^{3}$, PhD; Kathryn Fisher ${ }^{2}$, PhD; Kathya Jovel Ruiz ${ }^{1}$, BSc; Sunita Ghosh ${ }^{4}, \mathrm{PhD}$; Shelley Peacock ${ }^{5}, \mathrm{PhD}$; Maureen Markle-Reid ${ }^{2}, \mathrm{PhD}$; Allison Williams ${ }^{6}, \mathrm{PhD}$; Jean Triscott ${ }^{7}$, MD; Jennifer Swindle ${ }^{1}$, PhD

\footnotetext{
${ }^{1}$ Faculty of Nursing, University of Alberta, Edmonton, AB, Canada

${ }^{2}$ School of Nursing, Faculty of Health Sciences, McMaster University, Hamilton, ON, Canada

${ }^{3}$ School of Public Health and Health Systems, University of Waterloo, Waterloo, ON, Canada

${ }^{4}$ Cancer Care, Alberta Health Services, Edmonton, AB, Canada

${ }^{5}$ College of Nursing, University of Saskatchewan, Saskatoon, SK, Canada

${ }^{6}$ School of Geography and Earth Sciences, McMaster University, Hamilton, ON, Canada

${ }^{7}$ Faculty of Medicine and Dentistry, University of Alberta, Edmonton, AB, Canada
}

Corresponding Author:

Wendy Duggleby, PhD

Faculty of Nursing

University of Alberta

11405 87th Ave

Edmonton, AB, T6G 1C9

Canada

Phone: 17804928660

Email:wendy.duggleby@ualberta.ca

\begin{abstract}
Background: A self-administered Web-based intervention was developed to help carers of persons with Alzheimer disease and related dementias (ADRD) and multiple chronic conditions (MCC) deal with the significant transitions they experience. The intervention, My Tools 4 Care (MT4C), was evaluated during a pragmatic mixed methods randomized controlled trial with 199 carers. Those in the intervention group received free, password-protected access to MT4C for three months. MT4C was found to increase hope in participants at three months compared with the control group. However, in the intervention group, 22\% (20/92) did not use MT4C at all during the three-month period.
\end{abstract}

Objective: This mixed methods secondary analysis aimed to (1) examine differences at three months in the outcomes of hope, self-efficacy, and health-related quality of life (HRQOL) scores in users (ie, those who used MT4C at least once during the three-month period) compared with nonusers and (2) identify reasons for nonuse.

Methods: Data from the treatment group of a pragmatic mixed methods randomized controlled trial were used. Through audiotaped telephone interviews, trained research assistants collected data on participants' hope (Herth Hope Index; HHI), self-efficacy (General Self-Efficacy Scale; GSES), and HRQOL (Short-Form 12-item health survey version 2; SF-12v2) at baseline, one month, and three months. Treatment group participants also provided feedback on MT4C through qualitative telephone interviews at one month and three months. Analysis of covariance was used to determine differences at three months, and generalized estimating equations were used to determine significant differences in HHI, GSES, and SF-12v2 between users and nonusers of MT4C from baseline to three months. Interview data were analyzed using content analysis and integrated with quantitative data at the result stage.

Results: Of the 101 participants at baseline, $9(9 \%)$ withdrew from the study, leaving 92 participants at three months of which 72 (78\%) used MT4C at least once; 20 (22\%) participants did not use it at all. At baseline, there were no statistically significant differences in demographic characteristics and in outcome variables (HHI, GSES, and SF-12v2 mental component score and physical component score) between users and nonusers. At three months, participants who used MT4C at least once during the three-month period (users) reported higher mean GSES scores $(P=.003)$ than nonusers. Over time, users had significantly higher 
GSES scores than nonusers $(P=.048)$. Reasons for nonuse of MT4C included the following: caregiving demands, problems accessing MT4C (poor connectivity, computer literacy, and navigation of MT4C), and preferences (for paper format or face-to-face interaction).

Conclusions: Web-based interventions, such as MT4C, have the potential to increase the self-efficacy of carers of persons with ADRD and MCC. Future research with MT4C should consider including educational programs for computer literacy and providing alternate ways to access MT4C in addition to Web-based access.

Trial Registration: ClinicalTrials.gov NCT02428387; https://clinicaltrials.gov/ct2/show/NCT02428387

(J Med Internet Res 2019;21(10):e14254) doi: 10.2196/14254

\section{KEYWORDS}

Web-based intervention; carers; dementia; multiple chronic conditions; program evaluation

\section{Introduction}

Family carers (unpaid family or friends) of persons with Alzheimer disease and related dementias (ADRD) have been recognized worldwide as providers of the majority of care [1]. The need to support these family carers is well documented as they experience significant changes in their lives [2] that can negatively impact their physical and mental health [3,4]. Family carers have been found to seek information for themselves and others using computers, smartphones, or other electronic means more frequently than noncarers [5]. Web-based interventions to support family carers are increasingly becoming available and affordable, flexible, and accessible [6]. In a recent meta-analysis, Web-based interventions for family carers were found to have positive outcomes such as increased mental health [7] and self-efficacy [8]. However, carers have also reported barriers to using Web-based interventions such as difficulty with language and computer literacy [9] and with navigation of the websites [10]. The limited interaction with other carers when using Web-based interventions has also been a concern $[11,12]$.

A Web-based intervention, My Tools 4 Care (MT4C), was developed to support family carers of persons with ADRD and multiple chronic conditions (MCC). MT4C was initially developed as a hard copy workbook that was piloted and showed promise in terms of helping family carers of persons with dementia [13]. The next step was to work with Atmist (Web developers), the research team, and family carers to develop a feasible, acceptable, and easy-to-use Web-based version. MT4C [14] is a self-administered, flexible, tailored intervention as carers decide which activities they wish to engage in and when. It can be used on a computer, tablet, or smartphone. MT4C was evaluated during a pragmatic mixed methods randomized control trial with 199 carers between June 2015 and April 2017 and was found to significantly increase participants' hope in the treatment group compared with the control group [15].

Of 92 participants in the treatment group, $20(22 \%)$ did not use MT4C over the three-month period. This is similar to other Web-based internet intervention studies that reported a substantial number of treatment group participants who did not use the interventions [10,12]. The Consolidated Standards of Reporting Trials-Electronic Health guidelines for reporting Web-based intervention trials recommend the common practice of using an intent-to-treat analysis in trials that include users and nonusers [16]. However, it is also important to examine the data of nonuser participants [17]. This paper reports a secondary analysis to provide insight into the characteristics and the difference in outcomes of hope, general self-efficacy, and quality of life in users versus nonusers of MT4C. This examination of MT4C will inform the evaluation of future Web-based interventions for family carers of persons with ADRD and MCC.

The aim of this secondary analysis was to examine differences in outcomes (hope, self-efficacy, and quality of life) in participants who used MT4C (users) in a three-month period versus those who did not use it (nonusers) and to examine reasons for nonuse. The following research questions guided the study:

1. Was there a significant difference in demographic characteristics in the users versus nonusers?

2. Was there a significant difference in hope, self-efficacy, and quality of life at three months in users versus nonusers?

3. What were the reasons for nonuse from the qualitative data collected for nonusers?

Those who did not use MT4C were not a control group, as they had the opportunity to use it. The nonusers had been randomly assigned to the treatment group but chose not to use MT4C. We hypothesized that the users of MT4C will report a statistically significant increase in hope, self-efficacy, and quality of life compared with the nonusers.

\section{Methods}

\section{Design}

A detailed protocol [18] and 2 articles describing MT4C and its evaluation have been published elsewhere [15,19]; thus, only details relevant to this secondary analysis are provided herein. Similar to the pragmatic trial, this study utilized a mixed methods comparative design. The data reported here focus on family carers allocated to the treatment group $(\mathrm{N}=101)$. Qualitative data from the interviews and quantitative data from the treatment group collected during the original study were integrated in the results stage. Qualitative data were used to understand the quantitative results.

\section{Ethics}

The primary study received ethical approval from the University of Alberta Health Research Ethics Board (No. Pro00048721) and the Hamilton Integrated Research Ethics Board (No. 
15-309). The initial ethics application included the ability to conduct a secondary analysis of the data.

\section{Recruitment of Participants}

Family carers were invited to participate if they were over the age of 18 years and were caring for a person aged 65 years or older living with ADRD and MCC in the community. In addition, they needed to have a valid email address and access to a computer. Family carers were recruited through multiple community organizations including Alzheimer Society branches in each province and advertisements in local community newspapers in Alberta. If they met the eligibility criteria, they were asked to contact the researchers. Participants were randomly assigned to a treatment or control group using stratified permuted block randomization. Different consent forms (one for the treatment group and one for the control group) were used to blind participants regarding their group assignment.

Once consent was obtained, trained data collectors collected all data (baseline, one month, and three months) via telephone and entered it into REDCap, a secure, password-protected Web-based data collection service, offered at the University of Alberta. Data collection occurred from June 2015 to April 2017 and is reported in more detail in the study protocol [18]. Data collection procedures for the treatment group and the number of participants at each period are presented in Figure 1.

Figure 1. Data collection procedures and numbers of participants. ADRD: Alzheimer disease and related dementias; GSES: general self-efficacy scale; HHI: herth hope index; MT4C: My Tools 4 Care; SF-12v2: short-form 12-item health survey.

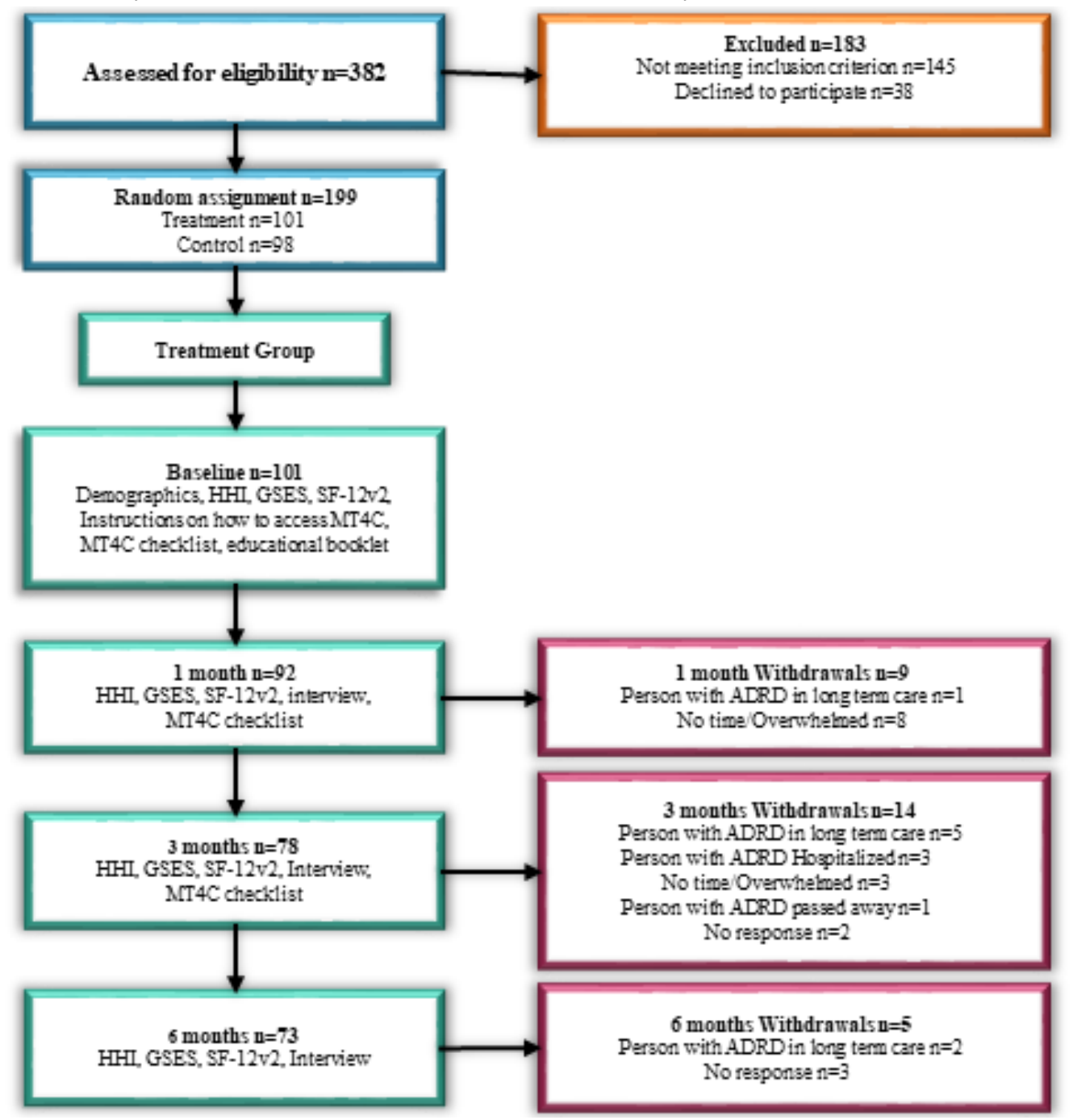

\section{Intervention}

Following baseline interviews, participants in the treatment group received free, password-protected access to MT4C for three months. Research assistants, using a standardized script, instructed the participants to access MT4C at their convenience on a computer, tablet, or smartphone. A follow-up email was sent to participants in the treatment group with instructions on how to access the site and their login information. After logging in, the first page provided instructions on how to use MT4C.
Each Web page also contained a menu outlining the sections that comprised MT4C: (1) about me; (2) common changes to expect; (3) frequently asked questions; (4) resources; (5) important health information; and (6) calendar. MT4C also provided options to add formatted text, photos, and PDF files in certain sections. All information entered by participants was treated confidentially and was not accessible to the study team. Participants also received an electronic copy of the Alzheimer Society's The Progression of Alzheimer's Disease booklet [20], a copy of the study questionnaires, and the MT4C toolkit 
checklist intended for participants to record their use of the MT4C site. During the one-month interview, trained data collectors encouraged nonusers to use MT4C. No changes or alterations were made to MT4C during the study.

\section{Measures}

\section{Data Collection}

Data collected at baseline included age, gender, years in caregiver role, employment status, ethnicity, household income before taxes, living arrangement, the relationship to the person with ADRD and MCC, and any assistance with caregiving. Data regarding sex, age, and number of chronic conditions of the person with ADRD and MCC were also collected.

Data on family carers' hope, self-efficacy, and health-related quality of life (HRQOL) were collected at baseline, one month, three months, and 6 months by trained research assistants using the measures outlined in the following section. Figure 1 outlines the data collection procedures.

\section{Herth Hope Index}

To measure hope using the Herth Hope Index (HHI), participants answered 12 questions scored on a Likert-type scale from 1 (strongly disagree) to 4 (strongly agree). A total hope score (range 12-48) was reported (higher scores indicate higher hope) along with 3 subscales: (1) temporality and future, (2) positive readiness and expectancy, and (3) interconnectedness. The HHI has a test-retest reliability of $0.91(P<.05)$ and criterion-related validity $\mathrm{r}$ of 0.81 to $0.92(P<.005)$ [21].

\section{General Self-Efficacy Scale}

The General Self-Efficacy Scale (GSES) is a measure of perceived self-efficacy or belief that one can deal with difficult tasks or cope with adversity using a 10-item 4-point scale [22]. Total scores ranged from 10 to 40 . It is a reliable tool with a Cronbach alpha coefficient ranging from .76 to $.90(P<.05)$.

\section{Short Form 12-Item Health Survey}

The SF-12v2 is a measure of HRQOL, consisting of 12 questions measuring 8 domains of well-being and functioning (physical functioning, role functioning, bodily pain, general health, vitality, social functioning, emotional health, and mental health) $[23,24]$. Responses to the 12 questions are summarized by 2 scores: physical component summary score (PCS; estimated test-retest reliability of $r=0.89$ ) and a mental component summary score (MCS; estimated test-retest reliability $r=0.86$ ) that range from 0 to 100 [25].

\section{Qualitative Interviews}

Interviews were semistructured and completed over the telephone by a trained research assistant. All interviews were audio-recorded and transcribed verbatim by an experienced transcriptionist. Participants were asked questions such as What were you thinking about when you worked on MT4C?; Did it help you deal with significant changes?; What did you like best?; and What did you like least? As indicated by the larger study protocol, qualitative interviews were conducted with a subsample of study participants. For those in the treatment group, 6 of the 20 nonusers were interviewed using semistructured interviews.

\section{My Tools 4 Care Checklist (Use of My Tools 4 Care)}

The MT4C checklist was developed by the research team and was used to collect data on the participants' use of MT4C. The checklist was intended for participants to keep track of the number of times they accessed each section of MT4C and the amount of time spent on each section. Data from the checklist were used to determine the use of MT4C at one month and three months.

Participants also made comments on the checklist about their nonuse, which were considered qualitative data for this study.

\section{Data Analysis}

Data were entered in SPSS version 24 (IBM) and checked for accuracy by a trained research assistant. Before data analysis, participants were divided into 2 groups: (1) participants who used MT4C at least once over three months and (2) participants who did not use MT4C within the three-month period. Use of MT4C was captured using a dichotomous variable, where $1=$ used MT4C at least once during the three-month intervention period and $0=$ did not use MT4C during the three-month intervention period.

\section{Participant Characteristics}

Means and SDs were used to represent continuous demographic characteristics of participants and persons with ADRD and MCC; categorical data were reported with numbers and percentages. Chi-squared statistical analysis and $t$ tests were used to determine differences in demographic characteristics between the groups.

\section{Outcome Measures}

Analysis of covariance (ANCOVA) was used to test the differences in outcome variables between users and nonusers at three months. Separate ANCOVA models were run for each outcome, with the three-month outcome as the dependent variable, group (users and nonusers) as the independent variable, and baseline value of the outcome as the covariate. A $P$ value of <.05 was used for statistical significance, and 2-sided tests were used. A complete case analysis was used, which means we did not impute for missing data (ie, we used people who had a complete record for the 3 time points baseline, one month, and three months).

Generalized estimating equations (GEE) were used to determine differences between the 2 groups (users vs nonusers) over time for the main outcome variables of HHI, GSES, and SF-12v2 MCS and PCS. GEE is an alternative statistical method appropriate for repeated measures data and is more flexible than other methods (eg, repeated measures ANCOVA) because it does not require that outcomes be normally distributed and can handle both continuous and dichotomous outcomes. It can also be used with small sample sizes [26]. Use was captured dichotomously at 3 time points in the GEE models, with use $=0$ for all intervention group participants at baseline, and 1 (used) or 0 (did not use) at one month and three months (depending on use reported by participants at these time points). Separate GEE models were run for each outcome (primary and secondary). 


\section{Reasons for Nonuse of My Tools 4 Care}

Nonusers' MT4C checklist and qualitative data from interviews were analyzed using content analysis [27] and informed the quantitative data in the results phase. Transcripts were read overall by a trained research assistant and organized into categories to address the study purpose. Trustworthiness of the data was maintained by keeping an audit trail and using participants' words as much as possible.

\section{Results}

\section{Comparison of User and Nonuser Participants}

A total of 101 participants were allocated to the treatment group at baseline. Following baseline measures, 9 participants withdrew and the remaining 92 participants received instructions on how to access MT4C. Figure 1 illustrates the number of persons at baseline and three months. The mean age of all participants in the treatment group was 63.5 years (SD 12.0), and they had been carers for an average of 4.1 years (SD 3.9).
The majority of participants were female $(73 / 92,79 \%)$, white (84/92, 91\%), were living with a person with ADRD (63/92, $62 \%)$, and were the spouse of a person with ADRD (48/92, $52 \%)$. No statistically significant differences were found in the demographic characteristics of users and nonusers (Table 1).

The means and SDs of the outcome measures (HHI, GSES, MCS, and PCS for each group at baseline and three months) are presented in Table 2.

Table 3 provides the ANCOVA results for each outcome. The group variable (users and nonusers) was significant for the GSES outcome $(P=.003)$, indicating that the use of MT4C during the three-month period was associated with an increase in GSES from baseline to three months. The use of MT4C was not associated with significant differences in the other outcomes.

Table 4 provides the GEE model results and shows that the use of MT4C was associated with an increase in GSES over three months $(P=.048)$. The use of MT4C was not associated with significant changes in the other outcomes. 
Table 1. My Tools 4 Care users versus nonusers: baseline comparison characteristics.

\begin{tabular}{|c|c|c|c|c|}
\hline Characteristics & Used MT4C $^{\mathrm{a}}(\mathrm{N}=72)$ & Did not use MT4C $(\mathrm{N}=20)$ & Total sample $(\mathrm{N}=92)$ & $P$ value \\
\hline \multicolumn{5}{|l|}{ Carers } \\
\hline \multicolumn{5}{|l|}{ Gender, n (\%) } \\
\hline Male & $14(19)$ & $5(25)$ & $19(20)$ & .59 \\
\hline Female & $58(80)$ & $15(75)$ & $73(79)$ & .59 \\
\hline Age (years), mean (SD) & $62.8(12.2)$ & $65.8(11.3)$ & $63.5(12.0)$ & .38 \\
\hline Caregiving (years), mean (SD) & $3.9(4.0)$ & $4.8(3.6)$ & $4.1(3.9)$ & .38 \\
\hline Education (years), mean (SD) & $14.2(2.9)$ & $14.2(2.8)$ & $14.2(2.9)$ & .10 \\
\hline Chronic conditions, mean (SD) & $2.3(1.6)$ & $2.2(1.3)$ & $2.2(1.6)$ & .86 \\
\hline \multicolumn{5}{|l|}{ Marital status, n (\%) } \\
\hline Married or living with someone & $60(83)$ & $17(85)$ & $77(84)$ & .87 \\
\hline Single, widowed, divorced/separated & $12(17)$ & $3(15)$ & $15(16)$ & .87 \\
\hline \multicolumn{5}{|l|}{ Ethnicity, n (\%) } \\
\hline White & $66(9)$ & $18(90)$ & $84(9)$ & .97 \\
\hline Other & $5(7)$ & $2(10)$ & $7(8)$ & .97 \\
\hline \multicolumn{5}{|l|}{ Employed, n (\%) } \\
\hline Yes & $31(4)$ & $3(15)$ & $34(3)$ & .05 \\
\hline No & $41(57)$ & $16(84)$ & $57(6)$ & .05 \\
\hline \multicolumn{5}{|l|}{ Living with care recipient, $\mathrm{n}(\%)$} \\
\hline Yes & $50(6)$ & $13(6)$ & $63(68)$ & .71 \\
\hline No & $22(31)$ & $7(35)$ & $29(31)$ & .71 \\
\hline \multicolumn{5}{|l|}{ Relationship to care recipient, n (\%) } \\
\hline Husband/wife/life partner & $37(51)$ & $11(55)$ & $48(52)$ & .77 \\
\hline Other & $35(9)$ & $9(45.0)$ & $44(48)$ & .77 \\
\hline \multicolumn{5}{|l|}{ Finances meet needs, $n(\%)$} \\
\hline Completely, very well, adequately & $60(8)$ & $14(7)$ & $74(80)$ & .18 \\
\hline With some difficulty, not very well, totally inadequate & $12(17)$ & $6(30)$ & $18(19)$ & .18 \\
\hline \multicolumn{5}{|l|}{ Household income, n (\%) } \\
\hline$<40,000$ & $17(24)$ & $5(25)$ & $22(24)$ & .99 \\
\hline$>40,000$ and $<70,000$ & $18(25)$ & $4(20)$ & $22(24)$ & .99 \\
\hline$>70,000$ & $26(36)$ & $8(40)$ & $34(37)$ & .99 \\
\hline No response & $11(15)$ & $3(15)$ & $14(15)$ & .99 \\
\hline \multicolumn{5}{|l|}{ Assistance with caring, n (\%) } \\
\hline Yes & $49(68)$ & $15(75)$ & $64(70)$ & .55 \\
\hline No & $23(32)$ & $5(25)$ & $28(30)$ & .55 \\
\hline \multicolumn{5}{|l|}{ Care recipient } \\
\hline \multicolumn{5}{|l|}{ Gender, mean (\%) } \\
\hline Male & $37(51)$ & $11(55)$ & $48(52)$ & .77 \\
\hline Female & $35(49)$ & $9(45)$ & $44(48)$ & .77 \\
\hline Age (years), mean (SD) & $79.6(7.7)$ & $82.5(6.5)$ & $80.2(7.5)$ & .13 \\
\hline Chronic conditions, mean (SD) & $10.6(4.2)$ & $10.1(4.1)$ & $10.5(4.2)$ & .63 \\
\hline
\end{tabular}

${ }^{\mathbf{a}}$ MT4C: My Tools 4 Care. 
Table 2. Mean and SD of outcomes at baseline and three months for users and nonusers.

\begin{tabular}{lll}
\hline Outcomes & Users MT4C $(\mathrm{N}=72)$, mean $(\mathrm{SD})$ & Nonusers MT4C $(\mathrm{N}=20)$, mean $(\mathrm{SD})$ \\
\hline Outcomes at baseline & $50.80(12.01)$ & $50.51(9.62)$ \\
PCS $^{\mathrm{b}}$ & $46.41(10.38)$ & $44.19(11.66)$ \\
MCS $^{\mathrm{c}}$ & $39.08(4.72)$ & $37.78(6.16)$ \\
HHI $^{\mathrm{d}}$ & $32.41(4.15)$ & $31.37(4.17)$ \\
GSES $^{\text {e }}$ & & $48.20(8.83)$ \\
Outcomes at one month & $50.74(11.14)$ & $45.83(12.89)$ \\
PCS & $47.57(10.26)$ & $38.61(5.92)$ \\
MCS & $39.45(5.07)$ & $30.02(4.92)$ \\
HHI & $32.99(4.01)$ & \\
GSES & & $50.37(7.84)$ \\
Outcomes at three months & $50.25(10.99)$ & $44.69(12.02)$ \\
PCS & $47.48(9.74)$ & $38.52(5.70)$ \\
MCS & $39.89(5.18)$ & $29.21(6.19)$ \\
HHI & $32.76(4.43)$ & \\
GSES & & \\
\hline
\end{tabular}

${ }^{\mathrm{a}}$ MT4C: My Tools 4 Care.

${ }^{b} \mathrm{PCS}$ : physical component score (SF-12v2).

${ }^{\mathrm{c}} \mathrm{MCS}$ : mental component score (SF-12v2).

${ }^{\mathrm{d}} \mathrm{HHI}$ : herth hope index.

${ }^{\mathrm{e}} \mathrm{GSES}$ : general self-efficacy scale. 
Table 3. Analysis of covariance results for outcomes from baseline to three months for users versus nonusers (group).

\begin{tabular}{|c|c|c|}
\hline Outcome & Parameter estimate $(95 \% \mathrm{CI})$ & $P$ value \\
\hline \multicolumn{3}{|l|}{ SF-12v2 ${ }^{\mathrm{a}}\left(\mathrm{PCS}^{\mathrm{b}}\right.$ and MCS $\left.\mathrm{M}^{\mathrm{c}} ; \mathrm{n}=76\right)$} \\
\hline \multicolumn{3}{|l|}{ PCS at three months } \\
\hline Intercept & $16.09(8.60$ to 23.58$)$ & $<.001$ \\
\hline PCS_baseline & $0.70(0.56$ to 0.83$)$ & $<.001$ \\
\hline Group & $-1.36(-5.43$ to 2.72$)$ & .51 \\
\hline \multicolumn{3}{|l|}{ MCS at three months } \\
\hline Intercept & $16.77(6.03$ to 27.51$)$ & .003 \\
\hline MCS at baseline & $0.59(0.39$ to 0.79$)$ & $<.001$ \\
\hline Group & $2.79(-2.35$ to 7.93$)$ & .28 \\
\hline \multicolumn{3}{|l|}{$\mathrm{HHI}^{\mathrm{d}}(\mathrm{n}=78)$} \\
\hline \multicolumn{3}{|l|}{ HHI factor 1 at three months } \\
\hline Intercept & $2.16(-0.48$ to 4.80$)$ & .11 \\
\hline $\mathrm{HHI}$ factor 1 at baseline & $0.81(0.61$ to 1.00$)$ & $<.001$ \\
\hline Group & $0.59(-0.35$ to 1.53$)$ & .22 \\
\hline \multicolumn{3}{|l|}{ HHI factor 2 at three months } \\
\hline Intercept & $4.21(1.75$ to 6.67$)$ & .001 \\
\hline HHI factor 2 at baseline & $0.67(0.49$ to 0.84$)$ & $<.001$ \\
\hline Group & $0.49(-0.29$ to 1.26$)$ & .22 \\
\hline \multicolumn{3}{|l|}{ HHI factor 3 at three months } \\
\hline Intercept & $4.62(2.09$ to 7.15$)$ & $<.001$ \\
\hline $\mathrm{HHI}$ factor 3 at baseline & $0.62(0.43$ to 0.81$)$ & $<.001$ \\
\hline Group & $0.49(-0.40$ to 1.38$)$ & .28 \\
\hline \multicolumn{3}{|c|}{ HHI total score at three months } \\
\hline Intercept & $5.50(-1.62$ to 12.62$)$ & .13 \\
\hline $\mathrm{HHI}$ at baseline & $0.84(0.66$ to 1.01$)$ & $<.001$ \\
\hline Group & $1.47(-0.62$ to 3.56$)$ & .17 \\
\hline \multicolumn{3}{|l|}{$\operatorname{GSES}^{\mathrm{e}}(\mathrm{n}=77)$ at three months } \\
\hline Intercept & $4.14(-2.59$ to 10.86$)$ & .22 \\
\hline GSES at baseline & $0.78(0.58$ to 0.98$)$ & $<.001$ \\
\hline Group & $3.23(1.12$ to 5.33$)$ & $.003^{\mathrm{f}}$ \\
\hline
\end{tabular}

${ }^{\mathrm{a}} \mathrm{SF}-12 \mathrm{v} 2$ : short-form 12-item health survey.

${ }^{b}$ PCS: physical component score (SF-12v2).

${ }^{\mathrm{c}} \mathrm{MCS}$ : mental component score (SF-12v2).

${ }^{\mathrm{d}} \mathrm{HHI}$ : herth hope index.

${ }^{\mathrm{e}}$ GSES: general self-efficacy scale.

${ }^{\text {f }}$ Significant at $P<.05$. 
Table 4. Generalized estimating equation results for outcomes (repeated measures analysis over three months [time $2=$ one month; time $3=$ three months]) for users compared with nonusers. Time 2 (one month from baseline) was not a significant factor in time 3 outcomes.

\begin{tabular}{|c|c|c|c|}
\hline Outcome & Estimate & $\mathrm{SE}(95 \% \mathrm{CI})$ & $P$ value \\
\hline \multicolumn{4}{|l|}{$S F-12 v 2^{a}$} \\
\hline \multicolumn{4}{|l|}{$\mathbf{P C S}^{\mathbf{b}}$} \\
\hline \multicolumn{4}{|l|}{ Time $3^{c}$} \\
\hline Group (users) & -2.03 & $1.68(-5.32$ to 1.27$)$ & .23 \\
\hline Time 2 & -0.23 & $0.94(-2.07$ to 1.60$)$ & .80 \\
\hline \multicolumn{4}{|l|}{$\operatorname{MCS}^{d}$} \\
\hline \multicolumn{4}{|l|}{ Time $3^{\mathrm{c}}$} \\
\hline Group (users) & 0.89 & $1.70(-2.44$ to 4.21$)$ & .60 \\
\hline Time 2 & -0.15 & $1.06(-2.22$ to 1.92$)$ & .89 \\
\hline \multicolumn{4}{|l|}{$\mathrm{HHI}^{\mathrm{e}}$ total } \\
\hline \multicolumn{4}{|l|}{ Time $3^{c}$} \\
\hline Group (users) & -0.38 & $0.86(-2.06$ to 1.30$)$ & .66 \\
\hline Time 2 & -0.44 & $0.52(-1.45$ to 0.58$)$ & .40 \\
\hline \multicolumn{4}{|l|}{ GSES $^{f}$} \\
\hline \multicolumn{4}{|l|}{ Time $3^{c}$} \\
\hline Group (users) & 1.55 & 0.78 (0.01 to 3.09$)$ & $.048^{\mathrm{g}}$ \\
\hline Time 2 & 0.06 & $0.42(-0.77$ to 0.89$)$ & .89 \\
\hline
\end{tabular}

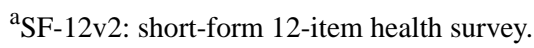

${ }^{b}$ PCS: physical component score (SF-12v2).

${ }^{\mathrm{c}}$ Reference group.

${ }^{\mathrm{d}}$ MCS: mental component score (SF-12v2).

${ }^{\mathrm{e}} \mathrm{HHI}$ : herth hope index.

${ }^{\mathrm{f}}$ GSES: general self-efficacy scale.

${ }^{\mathrm{g}}$ Significant at $P<.05$.

\section{Reasons for Nonuse of My Tools 4 Care}

Reasons for nonuse of MT4C reported in the qualitative data included the following: caregiving demands; problems accessing and navigating the site; and preference for paper or in-person contact. Participants reported being consumed with the role of caregiving and as a result did not have enough time to use MT4C. As one participant said: “....and I got to admit that it was, uh, something that, uh, I didn't go onto too much, just strictly because of all the other things that were-were going on this past month." Those who were able to find a little bit of time to look at MT4C found they were quickly distracted by the care recipient and ultimately did not use it. One participant described having to stop using MT4C to tend to her husband: "Well, um, I just finished reading it, and — and —and, then, I had to go off because I had to go help my husband."

Caregiving demands also resulted in nonuser participants feeling stressed. As one participant said: "I'm extremely stressed with taking care of my wife, and so I lost the email with login instructions." Another indicated that the lack of energy was a factor "...[I] work full time early morning to late evening....and at the end of the day, I don't have the energy or time to go on the computer."

Problems accessing MT4C were related to poor internet connections, computer literacy, and difficulties navigating the site. Nonusers who lived in rural areas reported poor internet connections: "...my internet connection at home is poor-I live in a rural area." Several nonusers described their lack of experience with computers (computer literacy): "No, it-it's, uh, as far as the computer is concerned, it's the-the operator of it that's at fault."; another said: "Um, well, I get frustrated at myself when, you know, I'm working on the website..."

In terms of difficulty navigating the site, participants described forgetting the link to log in and difficulty printing instructions for the site. A participant described her frustration with not being able to find where she had previously been working on the site after being interrupted by her husband, "he kept interrupting me. Then, I couldn't find where I left off to continue..." Caregiving demands coupled with navigating the site were the reason this participant did not use MT4C. 
Nonusers also seemed to have a preference for access to hard copy or paper format of MT4C and interaction with other carers. As a participant said, "...Sometimes, you actually have to have something printed in front of you, uh, and I'm better off-I'm better with paper. In some instances, to sit and reflect, I'm not really good at what-I'm not really one of those people who can do it all on-line." This participant described his lack of experience with working on the Web, but also suggested his preference was for paper. Another participant suggested a preference for social interaction rather than Web-based tools: "I think-I think I know-and this is [chuckles]—this isn't specific to this Toolkit, but it sort of relates to it: um, I think I'm the kind of person who gets a lot more out of, you know, actual social interaction around something."

The reasons for nonuse of MT4C, although reported as separate issues, appeared to be interrelated. For example, the lack of computer literacy meant it took more time to use MT4C, but with caregiving demands, less time was available. Furthermore, participants who are not computer literate became frustrated and thus preferred a paper format.

\section{Discussion}

\section{General Self-Efficacy}

The main findings of this study were a statistically significant difference between the users and nonusers of MT4C with regard to general self-efficacy (the confidence in their ability to deal with difficult situations). General self-efficacy significantly increased in the user group.

Other studies have found that general self-efficacy has a significant positive relationship with the quality of life of family carers of people with chronic illness [28]. For family carers of persons with dementia, self-efficacy has been found to have a significant relationship with health outcomes such as mental health $[29,30]$ and, in particular, is negatively correlated with depression $[31,32]$. In the larger study, hope was found to be positively associated with general self-efficacy [13]. When the hope of participants increased, so did their confidence in their ability to deal with difficult situations. However, in the larger study using the intent-to-treat analysis, which included nonusers, general self-efficacy was not found to be significantly different in the treatment versus the control group, but hope was. It was important to further examine differences between users and nonusers in the treatment group, as the finding that self-efficacy was higher in users versus nonusers supports the intervention model in which MT4C has the potential to increase quality of life by increasing self-efficacy.

\section{Reasons for Nonuse}

The qualitative data suggested that caregiving demands, accessibility to the site, and preference for a paper version or face-to-face interaction were barriers to use for nonuser participants. Caregiving demands with subsequent family carer lack of energy and feelings of stress are consistent with the findings from the qualitative data from all participants in the larger study [19]. Quality of life scores at each time period for users and nonusers were not significantly different; however, whether the nonuser group experienced a more pronounced lack of energy and higher levels of stress than those in the user group is unclear. Future research should potentially also measure fatigue and stress as possible barriers to the use of Web-based interventions.

Poor connectivity to the internet was described as a barrier to use of MT4C by nonuser participants. Web-based interventions have been considered to be of benefit particularly for rural populations because of considerations related to accessibility [33]. However, poor connectivity to the internet, particularly for persons in rural areas in Canada, is a barrier to the use of any Web-based intervention [34,35]. Poor connectivity should be a concern for any research with Web-based interventions and possibly an exclusion criterion for participants in efficacy and effectiveness trials.

Computer literacy (ie, the ability to use computers and related technology efficiently) appeared to be one of the barriers to using MT4C. Inclusion criteria for the study included access to a computer and an email address. However, in this study, a measure of computer literacy was not used. Park et al [36], following an integrated review of health-related internet use of family carers of children, suggested that Web-based interventions should also include educational programs to increase computer literacy. Although MT4C was previously determined to be easy to use, an additional tell me more feature could be embedded into the program to assist carers who have low computer literacy.

What is unclear from our study is if access issues and computer literacy resulted in some participant preferences for a paper format and/ or face-to-face supportive interactions. Moreover, the nonusers referred in their comments to in-person interaction with other carers not Web-based interaction with other carers. When interaction with other family carers was added to a Web-based intervention, caregiving demand and computer literacy were also found to have an impact on the perceived benefit of a Web-based intervention [37]. This suggests that Web-based interventions to support family carers of persons with ADRD and MCC should not be the only format for support, but opportunities to use a paper version of MT4C and in-person face-to-face interactions are also important.

\section{Limitations}

This study was a secondary analysis; thus, follow-up interviews with nonuser participants were not conducted. Follow-up interviews would have been completed to further explore participants' reasons for nonuse and to answer questions about the relationship between computer literacy and their preferences for a paper format. Low computer literacy and poor connectivity were also not considered as exclusion criteria for the study, possibly influencing the results.

Importantly, this comparison involves a sample that was not randomly assigned, thus limiting the generalizability of the study. Although there were no statistically significant differences in the demographic characteristics between users and nonusers, there may be a potential imbalance between the groups based on unmeasured contextual characteristics. The findings contribute to the developing model of the intervention; however, in future studies, potential mediators and moderators should be 
identified and their influence on the outcomes of the intervention should be evaluated.

\section{Conclusions}

The findings of this study reflect how comparisons of users and nonusers in Web-based intervention studies can improve Web-based interventions and the design of future studies. The statistically significant higher levels of general self-efficacy (or the confidence in the ability to deal with difficult situations) in users of MT4C is an important finding. Family carers of persons with dementia have reported significantly less self-efficacy than carers of persons without dementia [38]. As such, MT4C can potentially benefit family carers who are willing and able to use Web-based interventions. More research is needed to determine if adding an educational program for computer literacy may assist more family carers to access this Web-based intervention. In addition, future research should explore the use of MT4C in carers with diverse cultural backgrounds and languages.

\section{Acknowledgments}

This study is part of a program of research (Aging, Community and Health Research Unit) supported by the Canadian Institutes of Health Research Signature Initiative in Community-Based Primary Healthcare Funding (Reference Number: TTF 128261), MM-R's Canada Research Chairs Program, and WD's Endowed Research Chair University of Alberta. The authors wish to thank all of the study participants and their community partners: Alberta Caregivers Association, Alzheimer Society of Alberta and North West Territories, Alzheimer Society of Brant, Haldimand Norfolk, Hamilton and Halton, Alzheimer Society of Calgary, Alzheimer Society of Ontario, and Covenant Health Alberta. The authors also thank Tracy Chambers and the data collectors: Ann Cotton, Vanessa Hang, Melissa Northwood, Lori Pollard, and Tracy Wildeman.

\section{Conflicts of Interest}

None declared.

\section{References}

1. World Health Organization. 2012. Dementia: A Public Health Priority URL: https://apps.who.int/iris/bitstream/handle/ 10665/75263/9789241564458 eng.pdf;jsessionid=5634250F7FD71437CC5F71F333670A6D?sequence=1 [accessed 2019-03-13] [WebCite Cache ID 76qdBO8Ab]

2. Ploeg J, Northwood M, Duggleby W, McAiney CA, Chambers T, Peacock S, et al. Caregivers of older adults with dementia and multiple chronic conditions: exploring their experiences with significant changes. Dementia (London) 2019 Mar 6:1471301219834423 (epub ahead of print)(forthcoming)(forthcoming). [doi: 10.1177/1471301219834423] [Medline: 30841745]

3. Roth DL, Fredman L, Haley WE. Informal caregiving and its impact on health: a reappraisal from population-based studies. Gerontologist 2015 Apr;55(2):309-319 [FREE Full text] [doi: 10.1093/geront/gnu177] [Medline: 26035608]

4. Fonareva I, Oken BS. Physiological and functional consequences of caregiving for relatives with dementia. Int Psychogeriatr 2014 May;26(5):725-747 [FREE Full text] [doi: 10.1017/S1041610214000039] [Medline: 24507463]

5. Bangerter LR, Griffin J, Harden K, Rutten LJ. Health information-seeking behaviors of family caregivers: analysis of the health information national trends survey. JMIR Aging 2019 Jan 14;2(1):e11237. [doi: 10.2196/11237]

6. Guay C, Auger C, Demers L, Mortenson WB, Miller WC, Gélinas-Bronsard D, et al. Components and outcomes of internet-based interventions for caregivers of older adults: systematic review. J Med Internet Res 2017 Sep 19;19(9):e313 [FREE Full text] [doi: 10.2196/jmir.7896] [Medline: 28928109]

7. Sherifali D, Ali MU, Ploeg J, Markle-Reid M, Valaitis R, Bartholomew A, et al. Impact of internet-based interventions on caregiver mental health: systematic review and meta-analysis. J Med Internet Res 2018 Jul 3;20(7):e10668 [FREE Full text] [doi: 10.2196/10668] [Medline: 29970358]

8. Ploeg J, Ali MU, Markle-Reid M, Valaitis R, Bartholomew A, Fitzpatrick-Lewis D, et al. Caregiver-focused, web-based interventions: systematic review and meta-analysis (part 2). J Med Internet Res 2018 Oct 26;20(10):e11247 [FREE Full text] [doi: 10.2196/11247] [Medline: 30368439]

9. Chiu T, Marziali E, Colantonio A, Carswell A, Gruneir M, Tang M, et al. Internet-based caregiver support for Chinese Canadians taking care of a family member with Alzheimer disease and related dementia. Can J Aging 2009 Dec;28(4):323-336. [doi: 10.1017/S0714980809990158] [Medline: 19925698]

10. Lewis ML, Hobday JV, Hepburn KW. Internet-based program for dementia caregivers. Am J Alzheimers Dis Other Demen 2010 Dec;25(8):674-679. [doi: 10.1177/1533317510385812] [Medline: 21131674]

11. Ducharme F, Dubé V, Lévesque L, Saulnier D, Giroux F. An online stress management training program as a supportive nursing intervention for family caregivers of an elderly person. Can J Nurs Inform 2011;6(2):1-9 [FREE Full text]

12. Marziali E, Garcia LJ. Dementia caregivers' responses to 2 internet-based intervention programs. Am J Alzheimers Dis Other Demen 2011 Mar;26(1):36-43. [doi: 10.1177/1533317510387586] [Medline: 21282276]

13. Duggleby W, Swindle J, Peacock S. Self-administered intervention for caregivers of persons with Alzheimer's disease. Clin Nurs Res 2014 Mar;23(1):20-35. [doi: 10.1177/1054773812474299] [Medline: 23393291]

14. MyTools4Care. URL: https://www.mytools4care.ca/ [accessed 2019-07-01] 
15. Duggleby W, Ploeg J, McAiney C, Peacock S, Fisher K, Ghosh S, et al. Web-based intervention for family carers of persons with dementia and multiple chronic conditions (My Tools 4 Care): pragmatic randomized controlled trial. J Med Internet Res 2018 Jun 29;20(6):e10484 [FREE Full text] [doi: 10.2196/10484] [Medline: 29959111]

16. Eysenbach G. The law of attrition. J Med Internet Res 2005 Mar 31;7(1):e11 [FREE Full text] [doi: 10.2196/jmir.7.1.e11] [Medline: 15829473 ]

17. Eysenbach G, Consort-eHealth Group. Consort-eHealth: improving and standardizing evaluation reports of Web-based and mobile health interventions. J Med Internet Res 2011 Dec 31;13(4):e126 [FREE Full text] [doi: 10.2196/jmir.1923] [Medline: 22209829]

18. Duggleby W, Ploeg J, McAiney C, Fisher K, Swindle J, Chambers T, et al. Study protocol: pragmatic randomized control trial of an internet-based intervention (My tools 4 care) for family carers. BMC Geriatr 2017 Aug 14;17(1):181 [FREE Full text] [doi: 10.1186/s12877-017-0581-6] [Medline: 28806917]

19. Ploeg J, McAiney C, Duggleby W, Chambers T, Lam A, Peacock S, et al. A web-based intervention to help caregivers of older adults with dementia and multiple chronic conditions: qualitative study. JMIR Aging 2018 Apr 23;1(1):e2. [doi: 10.2196/aging.8475]

20. Alzheimer Society of Canada. 2013. Progression of Alzheimer's Disease: Overview URL: https://alzheimer.ca/sites/default/ files/files/national/progression-series/progression_overview_e.pdf [accessed 2019-03-13] [WebCite Cache ID 76qeUh3vE]

21. Herth K. Abbreviated instrument to measure hope: development and psychometric evaluation. J Adv Nurs 1992 Oct;17(10):1251-1259. [doi: 10.1111/j.1365-2648.1992.tb01843.x] [Medline: 1430629]

22. Schwarzer R. Self-Efficacy - Userpage. 2012. General Self-Efficacy Scale (GSE) URL: http://userpage.fu-berlin.de/health/ selfscal.htm [accessed 2019-03-13] [WebCite Cache ID 76qTcWX3y]

23. Markowitz JS, Gutterman EM, Sadik K, Papadopoulos G. Health-related quality of life for caregivers of patients with Alzheimer disease. Alzheimer Dis Assoc Disord 2003;17(4):209-214. [doi: 10.1097/00002093-200310000-00003] [Medline: 14657784]

24. Arango-Lasprilla JC, Lehan T, Drew A, Moreno A, Deng X, Lemos M. Health-related quality of life in caregivers of individuals with dementia from Colombia. Am J Alzheimers Dis Other Demen 2010 Nov;25(7):556-561. [doi: 10.1177/1533317510382287] [Medline: 20826708]

25. Ware JE. User's Manual for the SF-12v2 Health Survey (with a Supplement Documenting SF-12 Health Survey). Lincoln, Rhode Island, United States: Quality Metric Incorporated; 2002.

26. Thabane L, Mbuagbaw L, Zhang S, Samaan Z, Marcucci M, Ye C, et al. A tutorial on sensitivity analyses in clinical trials: the what, why, when and how. BMC Med Res Methodol 2013 Jul 16;13:92 [FREE Full text] [doi: 10.1186/1471-2288-13-92] [Medline: 23855337]

27. Graneheim UH, Lundman B. Qualitative content analysis in nursing research: concepts, procedures and measures to achieve trustworthiness. Nurse Educ Today 2004 Mar;24(2):105-112. [doi: 10.1016/j.nedt.2003.10.001] [Medline: 14769454]

28. Duggleby W, Williams A, Ghosh S, Moquin H, Ploeg J, Markle-Reid M, et al. Factors influencing changes in health related quality of life of caregivers of persons with multiple chronic conditions. Health Qual Life Outcomes 2016 May 27;14:81 [FREE Full text] [doi: $10.1186 / \mathrm{s} 12955-016-0486-7]$ [Medline: 27229926 ]

29. Zhang S, Edwards H, Yates P, Guo Q, Li C. Partial mediation role of self-efficacy between positive social interaction and mental health in family caregivers for dementia patients in Shanghai. PLoS One 2013;8(12):e83326 [FREE Full text] [doi: 10.1371/journal.pone.0083326] [Medline: 24386178]

30. Crellin NE, Orrell M, McDermott O, Charlesworth G. Self-efficacy and health-related quality of life in family carers of people with dementia: a systematic review. Aging Ment Health 2014;18(8):954-969 [FREE Full text] [doi: 10.1080/13607863.2014.915921] [Medline: 24943873]

31. Gallagher D, Mhaolain AN, Crosby L, Ryan D, Lacey L, Coen RF, et al. Self-efficacy for managing dementia may protect against burden and depression in Alzheimer's caregivers. Aging Ment Health 2011 Aug;15(6):663-670. [doi: 10.1080/13607863.2011.562179] [Medline: 21547745]

32. Rabinowitz YG, Saenz EC, Thompson LW, Gallagher-Thompson D. Understanding caregiver health behaviors: depressive symptoms mediate caregiver self-efficacy and health behavior patterns. Am J Alzheimers Dis Other Demen 2011 Jun;26(4):310-316. [doi: 10.1177/1533317511410557] [Medline: 21636582]

33. Deeken F, Rezo A, Hinz M, Discher R, Rapp MA. Evaluation of technology-based interventions for informal caregivers of patients with dementia - a meta-analysis of randomized controlled trials. Am J Geriatr Psychiatry 2019 Apr;27(4):426-445. [doi: 10.1016/j.jagp.2018.12.003] [Medline: 30642650]

34. Greenberg AJ, Haney D, Blake DK, Moser RP, Hesse BW. Differences in access to and use of electronic personal health information between rural and urban residents in the United States. J Rural Health 2018 Mar;34(Suppl 1):s30-s38 [FREE Full text] [doi: 10.1111/jrh.12228] [Medline: 28075508]

35. Federation of Canadian Municipalities. 2014. Broadband Access in Rural Canada: The Role of Connectivity in Building Vibrant Communities URL: https://fcm.ca/sites/default/files/documents/resources/report/broadband-access-rural-canada. pdf [accessed 2019-03-13] [WebCite Cache ID 76qTIUsqd]

36. Park E, Kim H, Steinhoff A. Health-related internet use by informal caregivers of children and adolescents: an integrative literature review. J Med Internet Res 2016 Mar 3;18(3):e57 [FREE Full text] [doi: 10.2196/jmir.4124] [Medline: 26940750] 
37. Vaughan C, Trail TE, Mahmud A, Dellva S, Tanielian T, Friedman E. Informal caregivers' experiences and perceptions of a web-based peer support network: mixed methods study. J Med Internet Res 2018 Aug 28;20(8):e257 [FREE Full text] [doi: 10.2196/jmir.9895] [Medline: 30154074]

38. Son J, Erno A, Shea DG, Femia EE, Zarit SH, Stephens MA. The caregiver stress process and health outcomes. J Aging Health 2007 Dec;19(6):871-887. [doi: 10.1177/0898264307308568] [Medline: 18165286]

\author{
Abbreviations \\ ADRD: Alzheimer disease and related dementias \\ ANCOVA: analysis of covariance \\ GEE: generalized estimating equations \\ GSES: general self-efficacy scale \\ HHI: herth hope index \\ HRQOL: health-related quality of life \\ MCC: multiple chronic conditions \\ MCS: mental component score (SF-12v2) \\ MT4C: My Tools 4 Care \\ PCS: physical component score (SF-12v2) \\ SF-12v2: short-form 12-item health survey
}

\author{
Edited by G Eysenbach; submitted 03.04.19; peer-reviewed by F Lanfranchi, M Usman; comments to author 08.07.19; revised version \\ received 08.08.19; accepted 18.08.19; published 17.10.19 \\ Please cite as: \\ Duggleby W, Ploeg J, McAiney C, Fisher K, Jovel Ruiz K, Ghosh S, Peacock S, Markle-Reid M, Williams A, Triscott J, Swindle J \\ A Comparison of Users and Nonusers of a Web-Based Intervention for Carers of Older Persons With Alzheimer Disease and Related \\ Dementias: Mixed Methods Secondary Analysis \\ J Med Internet Res 2019;21(10): 14254 \\ URL: https://www.jmir.org/2019/10/e14254 \\ doi: $10.2196 / 14254$ \\ PMID: 31625947
}

(CWendy Duggleby, Jenny Ploeg, Carrie McAiney, Kathryn Fisher, Kathya Jovel Ruiz, Sunita Ghosh, Shelley Peacock, Maureen Markle-Reid, Allison Williams, Jean Triscott, Jennifer Swindle. Originally published in the Journal of Medical Internet Research (http://www.jmir.org), 17.10.2019. This is an open-access article distributed under the terms of the Creative Commons Attribution License (https://creativecommons.org/licenses/by/4.0/), which permits unrestricted use, distribution, and reproduction in any medium, provided the original work, first published in the Journal of Medical Internet Research, is properly cited. The complete bibliographic information, a link to the original publication on http://www.jmir.org/, as well as this copyright and license information must be included. 